công cộng, Trường Đại học Y Hà Nội.

4. Nguyê̂n Bá Đức (2008). Phòng phát hiên sớm bệnh unng thư, NXB Y học Hà Nội.

5. Nguyê̂n Thị Quế Lâm (2017), Tìm hiểu một số yểu tố liên quan đến kiến thức, thái độ và thực hành về phòng chống bệnh ung thư vú ở phụ nữ thi xã Ninh Hòa, tỉnh Khánh Hòa, Đề tài cơ sở Trung tâm Truyền thông GDSK Khánh Hòa

6. Đào Trung Nguyên (2017), Kiến thức, thực hành về phòng và phát hiên sớm ung thư vú cúa phư nữ ở công ty cổ phân may 10 và một số yếu tố liên quan, Luận văn tốt nghiệp trường địa học $Y$ Hà Nội.
7. Đỗ Quốc Tiệp, Mai Xuân Sự, Phan Tiến Hoàng và công sư (2015). Nghiên cứu kiến thức của người dân về phòng chống bệnh ung thư tại Quảng Bình. Tạp chí Ung thư học Việt Nam, số 5/2015, tr.41-44.

8. Trân Văn Thuấn, Bùi Diệu, Nguyễn Bá Đức và cộng sự (2012). Gánh nặng bệnh ung thư và chiến lược phòng chống ung thư quốc gia đến năm 2020. Tap chí Ung thư học - Hội thảo quốc gia phòng chống ung thư lần thứ 16 tháng 10 năm 2012, Số 1 (2012).

9. Trân Văn Thuấn (2007), Sàng loc và phát hiện sớm bệnh ung thư vú, NXB Y học Hà Nội.

\title{
PHẪU THUÂTT NộI SOI ĐIỀU TRI UNG THƯ BUỒNG TRỨNG GIAI ĐOẠN SỚM TẠI BỆNH VIỆN UNG BƯỚU NGHỆ AN
}

\author{
Vũ Đình Giáp*, Nguyễn Khắc Tiến*, \\ Trần Bá Kiên*, Nguyễn Thế Trung*, Đoàn Thị Hồng Nhật*
}

TÓM TẮT

Mục tiêu: Nhận xét một số đặc điểm lâm sàng, cận lâm sàng và đánh giá kết quả sớm phẫu thuật nội soi điều trị ung thư biểu mô buồng trứng tại bệnh viện Ung bướu Nghê An. Phương pháp: Mô tả hồi cứu kết hợp tiến cứu. Kết quả: 28 bệnh nhân ung thư biểu mô buồng trứng với tuổi trung bình $50,5 \pm 11,8$. Kích thước khối u chiếm tỉ lệ cao nhất là $5-8 \mathrm{~cm}(57,14 \%)$. Giải phẫu bệnh ung thư biểu mô thanh dịch chiếm $42,86 \%$. Nồng độ CA12-5 tăng 71,43\% các trường hợp và có mối liển quan tới giai đoạn bệnh và thể GPB.Thời gian phẫu thuật trung bình $185 \pm 20,4$ phút (120-210 phút). Thời gian nằm viện sau mổ trung bình $8,78 \pm 1,73$ (7 - 14) ngày. Có 2 trường hợp võ u trong mố. Biến chứng sau mổ 3,57\% nhiểm trùng mỏm cắt và $3,57 \%$ nhiễm trùng vết mổ. Không có trường hợp nào chảy máu sau mổ. Kết Luận: Phẫu thuât nôi soi trong điều trị ung thư buồng trứng giai đoạn sớm là an toàn, hiệu quả, kết quả sớm đảm bảo về ung thư hoc. soi.

Tứ khóa: Ung thư buồng trứng, phẫu thuật nội

\section{SUMMARY}

OUTCOME OF LAPAROSCOPIC SURGERY FOR

EARLY STAGE OF EPITHELIAL OVARIAN CANCER IN NGHE AN ONCOLOGY HOSPITAL

Objective: To investigate amount of clinical and paraclinical features and to evaluate outcome of Laparoscopic surgery for stage1 of epithelial ovarian cancer in Nghê An Oncology Hospital. Methods: Retrospective- Prospective study. Results: Of the 28

*Bênh viên Ung Bướu Nghê An

Chịu trách nhiệm chính: Trần Bá Kiên

Email: kiente121311@gmail.com

Ngày nhận bài: 27.10 .2020

Ngày phản biên khoa hoc: 30.11.2020

Ngày duyệt bài: 9.12.2020 patients with mean ages is $50,5 \pm 11,8$. The serous epitheial carcinoma is confirmed by pathology $(42,86 \%)$. CA125 level is highly raised with $71,43 \%$ and is related to disease staging. Mean operative time is $185 \pm 20,4$ mins (120-210 mins). The mean time for recover postoperative period is $8,78 \pm 1,73(7-14)$ days. There are 2 cases of the intraoperative rupture tumor. The postoperative complications including: Vaginal cuff dehiscence Infection (3,57\%); wound infection $(3,57 \%)$ and Postoperative Hemorrhage is no recorded. Conclusions: Laparoscopic surgical staging of early ovarian cancer is safe, effective and and survival outcome seems acceptable.

Key words; epithelial ovarian cancer; laparoscopy

\section{I. ĐĂT VẤN ĐỀ}

Ung thư buồng trứng (UTBT) môt tronglà bênh ung thư nguyên nhân gây tử vong hàng đầu trong các bệnh UT phụ khoa. Bệnh chủ yếu xuất hiên ở tuổi mãn kinh, có khoảng hơn một nửa xuất hiện sau tuổi 60 [1],[2]. Theo GLOBOCAN 2018 thì trên thế giới năm 2018 có khoảng 295.414 ca ung thư buồng trứng và có 184.799 trường hợp tử vong do bệnh này tương ứng với tỷ lệ mới mắc và tử vong là $6,6 / 100.000$ dân và $3,9 / 100.000[1],[2]$. Tại Việt Nam số trường hợp mới mắc là 1500 và số trường hợp tử vong là $856[1]$.

Về điêuu tri, PT đóng vai trò chủ đạo, hóa chất bổ trợ sau PT được chỉ định ở phần lớn các giai đoạn ngoại trừ một số ít trường hợp giai đoạn sớm, nguy cơ thấp (giai đoạn $\mathrm{IA}, \mathrm{IB}$, độ mô học 1) [2], [3], [4]. Do chưa có một phương pháp sàng lọc thực sự có hiệu quả nên việc phát hiện và điều trị bệnh ở giai đoạn sớm là mong mỏi của tất cả các thầy thuốc UT phụ khoa cũng như là vấn đề then chốt trong cải thiện tiên lượng 
bệnh. Cùng với sự phát triển của khoa học kỹ thuật, PTNS ngày càng được áp dụng trong điêu trị ung thư đặc biệt ung thư phụ khoa giai đoạn sớm với khả năng kiểm soát và thời gian sông thêm tương đương với phẫu thuật mở bụng kinh điển nhưng có lợi ích rõ ràng như ít đau hơn, giảm các biến chứng, giảm thời gian nằm viện....[5], [6], [7].

Tại Việt Nam hiện nay chưa có nhiều nghiên cứu về phẫu thuật nội soi trong điều trị ung thư buông trứng. Vì vậy chúng tôi tiến hành nghiên cứu đề tàiĐánh giá kết quả sớm PTNS điều trị ung thư buồng tứng tại bệnh viện UBNA.

II. ĐỐI TƯợNG VÀ PHƯƠNG PHÁP NGHIÊN CứU

2.1. Đối tượng nghiên cứu. 28 bệnh nhân UTBMBT giai đoạn I được phẫu thuật nội soi tại bệnh viện UBNA từ tháng 01/2018 đến tháng 09/2020.

\section{Tiêu chuẩn lựa chọn}

- Bệnh nhân được chẩn đoán UTBT giai đoạn I theo FIGO 2018.

- Bệnh nhân đồng ý điều trị phẫu thuật nội soi tại BV UBNA

- Có chẩn đoán MBH đây đủ

- Có hồ sơ theo dõi đầy đủ

Tiêu chuẩn loại trừ

- Bệnh nhân UTBT đã điều trị phẫu thuật tại cơ sở khác không phải bệnh viện UBNA.

- Không có chẩn đoán mô bệnh học đây đủ rõ ràng

- Kèm theo một ung thư khác ngoài UTBT

$>$ Phẫu thuật

- Ghi nhận tổn thương đại thể trong ổ bụng

- Thăm dò, kiểm tra toàn bộ bề mặt phúc mạc và bề mặt các tạng trong ổ bụng.

- Chẩn đoán giai đoạn đại thể trong mổ

- Đối với giai đoạn I: định giai đoạn phải được tiến hành theo các bước:

+ Nếu có dịch tự do trong ổ bụng, đặc biệt ở vùng tiểu khung thì phải được lấy làm xét nghiệm tế bào học.

+ Không có dịch tự do trong ổ bụng thì tiến hành rửa ổ bụng nhiều vị trí như vùng tiểu khung, rãnh đại tràng hai bên, hố gan, mỗi nơi 50-100 ml sau đó hút ra làm xét nghiệm tế bào học.
+ Phẫu thuật triệt căn không để lại tổn thương đại thể theo trình tự:

- Cắt mạc nối lớn ngoài bó mạch bờ cong lớn dạ dày

- Kiểm tra hạch: kiểm tra khoang sau phúc mạc, đánh giá hạch chậu. Đường mở trên phúc mạc cơ thắt lưng chậu, có thể chỉ thực hiện một bên nếu khối u chì có một bên. Các hach lớn phải được vét bỏ làm xét nghiệm giải phẫu bệnh tức thì. Nếu không có di căn thì nên vét hạch chuẩn mực. Kiểm tra vùng cạnh động mạch chủ bụng. Lây bỏ các hạch lớn và các hạch mạc treo.

- Cắt phân phụ + tử cung toàn bộ

- Lấy bệnh phẩm qua đường âm đạo

2.2. Phương pháp nghiên cứu: Mô tả hôi cứu kết hợp tiến cứu

2.3. Xử lí số liệu: Nhập và xử lý số liệu bằng phân mềm SPSS 16.0

\section{KẾT QUẢ NGHIÊN CỨU}

3.1. Đặc điểm lâm sàng và cận lâm sàng

Bảng 3.1. Đặc điểm tuổi bệnh nhân

\begin{tabular}{|c|c|c|c|}
\hline $\mathbf{N}$ & $\mathbf{X} \pm$ SD & MIN & MAX \\
\hline 28 & $50,5 \pm 11,8$ & 35 & 70 \\
\hline
\end{tabular}

Bảng 3.2. Triệu chứng vào viện

\begin{tabular}{|c|c|c|}
\hline Triệu chứng & Số BN & Tỷ lệ (\%) \\
\hline Đầy tức bụng dưới & 14 & 50 \\
\hline Bụng to ra & 2 & 7,14 \\
\hline Tự sờ thấy u & 2 & 7,14 \\
\hline $\begin{array}{c}\text { Tình cờ qua khám } \\
\text { định kỳ }\end{array}$ & 10 & 35,71 \\
\hline
\end{tabular}

Bảng 3.3. Đặc điếm u trên siêu âm

\begin{tabular}{|c|c|c|}
\hline Đặc điếm u & Số BN & Tỷ lệ (\%) \\
\hline \multicolumn{3}{|l|}{ Cấu trúc u } \\
\hline U nang & 8 & 28,57 \\
\hline U hôn hợp & 14 & 50 \\
\hline U đặc & 6 & 21,43 \\
\hline \multicolumn{3}{|c|}{ Các dấu hiệu gợi ý u ác tính } \\
\hline Có vách không đều & 16 & 57,14 \\
\hline Có nụ sùi trong u & 18 & 64,29 \\
\hline Có dịch ổ bụng & 10 & 35,71 \\
\hline \multicolumn{3}{|l|}{ Kích thước u } \\
\hline$<5 \mathrm{~cm}$ & 6 & 21,43 \\
\hline $5-8 \mathrm{~cm}$ & 16 & 57,14 \\
\hline$>8 \mathrm{~cm}$ & 6 & 21,43 \\
\hline
\end{tabular}

Bảng 3.4. Môî liên quan giữa nồng độ CA 12.5 huyết thanh tại thời điểm chẩn đoán với giai đoạn bệnh

\begin{tabular}{|c|c|c|c|c|c|c|c|c|}
\hline \multirow{3}{*}{$\begin{array}{c}\text { Nồng đô } \\
\text { CA 12.5 } \\
\text { huyêt thanh }\end{array}$} & \multicolumn{4}{|c|}{ Giai đoạn } & & & \multirow{2}{*}{\multicolumn{2}{|c|}{ Tổng }} \\
\hline & \multicolumn{2}{|c|}{ IA } & \multicolumn{2}{|c|}{ IB } & & IC & & \\
\hline & $\mathbf{n}$ & $\%$ & $\mathbf{N}$ & $\%$ & $n$ & $\%$ & $\mathrm{n}$ & $\%$ \\
\hline$\leq 35 \mathrm{U} / \mathrm{ml}$ & 6 & 40 & 0 & 0 & 2 & 18,18 & 8 & 28,57 \\
\hline$>35 \mathrm{U} / \mathrm{ml}$ & 9 & 60 & 2 & 100 & 9 & 81,82 & 20 & 71,43 \\
\hline Tống & 15 & 100,0 & 2 & 100,0 & 11 & 100,0 & 75 & 100,0 \\
\hline
\end{tabular}


Bảng 3.5. Đăc điểm mô bênh hoc

\begin{tabular}{|c|c|c|}
\hline Mố bệnh học & Số BN & Tý lệ (\%) \\
\hline UTBM thanh dịch & 12 & 42,86 \\
\hline UTBM thế nhầy & 8 & 28,57 \\
\hline UTBM dạng nội mạc & 6 & 21,43 \\
\hline Thể khác & 2 & 7,14 \\
\hline Tống & $\mathbf{2 8}$ & $\mathbf{1 0 0}$ \\
\hline
\end{tabular}

3.2. Kết quả điêu trị.

Bảng 3.6. Thời gian phẫu thuật và thời gian năm viện

\begin{tabular}{|c|c|c|c|c|}
\hline & $\mathbf{N}$ & $\mathbf{X} \pm$ SD & MIN & MAX \\
\hline $\begin{array}{c}\text { Thời gian phâuu } \\
\text { thuật (phút) }\end{array}$ & 28 & $\begin{array}{c}185 \pm \\
20,4\end{array}$ & 120 & 210 \\
\hline $\begin{array}{c}\text { Thời gian nằm } \\
\text { viện (ngày) }\end{array}$ & 28 & $\begin{array}{c}8,12 \pm \\
1,73\end{array}$ & 7 & 14 \\
\hline
\end{tabular}

Bảng 3.7. Lượng máu mất trong mố

\begin{tabular}{|c|c|c|c|c|}
\hline & $\mathbf{N}$ & $\mathbf{X} \pm$ SD & MIN & MAX \\
\hline $\begin{array}{c}\text { Lượng máu } \\
\text { mất (ml) }\end{array}$ & 28 & $\begin{array}{c}202 \pm \\
85,2\end{array}$ & 120 & 312 \\
\hline
\end{tabular}

Bảng 3.8. Các biến chứng của phâuu thuật.

\begin{tabular}{|c|c|c|}
\hline & $\begin{array}{c}\text { Số lượng } \\
\text { BN }\end{array}$ & $\begin{array}{c}\text { Tỷ lệ } \\
\text { (\%) }\end{array}$ \\
\hline Nhiêmm trùng vết mố & 1 & 3,57 \\
Nhiếm trùng mỏm cắt & 1 & 3,57 \\
\hline Không biến chứng & 26 & \\
\hline
\end{tabular}

\section{BÀN LUÂN}

Kết quả nghiên cứu của chúng tôi cho thấy phần lớn $B N$ ở độ tuổi trên 40 tuổi, tuổi mắc trung bình là $50,5 \pm 11,8$ tuổi. Đa số BN đã mãn kinh chiếm tỷ lế $64,26 \%$. Kết quả nghiên cứu của chúng tôi cũng tương đồng với nghiên cứu Nguyễn Trọng Diệp (2012).

Về đặc điểm u trên siêu âmnghiên cứu của chúng tồi siêu âm phát hiện $100 \%$ các trường hợp có u buồng trứng. Về cấu trúc u, tỷ lệ u có thành phần hổn hợp (bao gồm cả thành phần dịch và đăc) và u đắc chiếm đa số các trường hợp $71,43 \%$, còn lại là $u$ dạng nang chiếm $28,57 \%$. Về các dấu hiệu gợi ý ác tính trên siêu âm, tỷ lệ u có nu sùi trong nang là cao nhất gặp $64,29 \%$ các trường hợp. Kết quả của chúng tôi cũng tương đồng với các nghiên cứu như của Nguyễn Trọng Diệp tỉ lệ u có thành phần hỗn hợp và u đặc là $74,7 \%$; Tỉ lệ u có nụ sùi cao nhất $66,7 \%$. Siêu âm đặc biệt là siêu âm đầu dò âm đạo kết hợp với Doppler màu có vai trò quan trong trong việc đánh giá tính chất lành-ác của một khối u buồng trứng. Các dấu hiệu gợi ý ác tính trên siêu âm bao gồm: u có thành phần hỗn hợp và đặc, có vách dày trên $3 \mathrm{~mm}$ và không đều, có nụ sùi trong u, dịch ổ bụng và tăng sinh mach trên Doppler màu...

Về thời gian phẫu thuật trung bình trong nghiên cứu của chúng tôi là $185 \pm 20,4$ phút. So sánh với phẫu thuật mở bụng kinh điển thì thời gian phẫu thuật nội soi lâu hơn. Về lượng máu mất trong mổ trong các nghiên cứu so sánh giữa PTNS và mổ mở thì PTNS đều cho kêt quả mất máu ít hơn. Kết quả của chúng tôi lượng máu mất trung bình là $202 \pm 85,2 \mathrm{ml}$. Kết quả các nghiên cứu khác như của Hua (2005) thì lượng máu mất trung bình nhóm PTNS là $280 \mathrm{ml}$ trong khi đó của phẫu thuật mở bụng là $346 \mathrm{ml}$. Các nghiên cứu khác cho kết quả tương tự: Chi (2005) $235 \mathrm{ml}$ so với $367 \mathrm{ml}$; Ghezzi (2007) $250 \mathrm{ml}$ so với 400ml; Bogani (2014) 300ml so với 400ml.

Về biến chứng sau mổ chỉ có 2 trường hợp có biến chứng: 1 trường hợp nhiễm trùng vết mổ troca rốn, 1 trường hợp nhiễm trùng mỏm cắt âm đạo. Cả 2 trường hợp đều được điều trị ổn định ngay sau đó. Ba nghiên cứu so sánh về ung thư buiông trứng sớm đã báo cáo ít biến chứng hậu phẫu hơn khi nội soi ổ bụng so với phẫu thuật mở ổ bụng (Hua 2005; Lee 2011; Park 2011a). Trong các nghiên cứu này, tỷ lệ truyền máu ở các nhóm nội soi ổ bụng dao động từ $0 \%$ đến $15 \%$, trong khi cần truyền máu ở $30 \%$ ở những phụ nữ phẫu thuật mổ mở [6]. PTNS thời gian phục hồi của bệnh nhân ngắn hơn, giảm đau sau phẫu thuật, thời gian phục hồi ngắn hơn và kết quả thẩm mỹ cao hơn đã giúp tăng nhu cầu của $\mathrm{BN}$ ưa thích nhiều với phương pháp nội soi [7]. Tuy nhiên hạn chế trong PTNS ung thư' buồng trứng là nguy cơ võ khối u trong PT cao hơn. Vì vậy hiện tại PTNS điều trị ung thư buồng trứng theo hướng dẫn của NCCN 2019 chỉ nên áp dụng cho ung thư biểu mô buồng trứng giai đoạn sớm và được thực hiện bởi phẫu thuật viên ung thư phụ khoa có kinh nghiệm phẫu thuật nội soi. Trong nghiên cứu của chúng tôi có 2 trường hợp võ u trong PT: 1 trường hợp làm tăng giai đoạn IB lên IC, còn 1 trường hợp IC được xác địch trước vỡ. Cả 2 trường hợp khối u có kích thước lớn và được thực hiện trong thời gian đầu chúng tôi triển khai. Tất cả trường hợp sau đó chúng tôi đều đã lên kế hoach chặt chẽ hơn trong lựa chọn bệnh nhân, đảm bảo điều kiện quan trọng là không làm tăng giai đoạn bệnh.

\section{KẾT LUÂN}

Phẫu thuâtt nội soi trong điều trị ung thư biểu mô buồng trứng giai đoạn I là an toàn, hiệu quả. So với phẫu thuật mở bụng kinh điển có nhiều lợi thế như ít đau hơn, giảm các biến chứng, giảm thời gian nằm viện và tăng tính thẩm mỹ.

\section{TÀl LIỆ THAM KHẢO}

1. Bray F., Ferlay J., Soerjomataram I., et al. 
(2018). Global cancer statistics 2018: GLOBOCAN estimates of incidence and mortality worldwide for 36 cancers in 185 countries. CA: a cancer journal for clinicians, 68(6). 394-424.

2. Reid B.M., Permuth J.B., Sellers T.A. (2017). Epidemiology of ovarian cancer: a review. Cancer biology \& medicine, 14(1). 9.

3. Feig B.W., Berger D.H., Fuhrman G.M. (2006). The MD Anderson surgical oncology handbook, Lippincott Williams \& Wilkins,

4. Allemani C., Weir H.K., Carreira $H_{.}$, et al. (2015). Global surveillance of cancer survival 1995-2009: analysis of individual data for 25676 887 patients from 279 population-based registries in 67 countries (CONCORD-2). The Lancet, 385(9972). 977-1010.
5. Weber S., McCann C.K., Boruta D.M., et al. (2011). Laparoscopic surgical staging of early ovarian cancer. Reviews in Obstetrics and Gynecology, 4(3-4). 117.

6. Falcetta F.S., Lawrie T.A., Medeiros L.R., et al. (2016). Laparoscopy versus laparotomy for FIGO stage I ovarian cancer. Cochrane Database of Systematic Reviews, (10).

7. Cho JE, Liu C, Gossner G, et al (2009). Laparoscopy and gynecologic oncology. Clin Obstet Gynecol.;52:313-326

8. Nguyê̂n Trọng Diêp (2012), Nhân xét đặc điểm lâm sàng, cận lấm sàng và kêt quả điều trị ung thư buồng trứng giai đoan sớm bằng phẫu thuật kết hợp hóa chất tai bệnh viện $K$, Luận văn bác sĩ nội trú. Trường Đại học Y Hà Nội.

\title{
ĐÁNH GIÁ HÌNH THÁI VÀ CHỨC NĂNG TIM THAI Ở SẢN PHỤ TIỀN SẢN GIẬT TẠI KHOA PHỤ SẢN VÀ VIỆN TIM MẠCH BỆNH VIỆN BẠCH MAI
}

\author{
Nguyễn Phương Thảo1, Phạm Thị Hồng Thi², \\ Phạm Bá $\mathrm{Nha}^{3}$, Nguyễn Thị Duyên ${ }^{1}$
}

\section{TÓM TẮT}

Mục tiêu: Đánh giá được sự thay đổi hình thái chức năng tim thai ở sản phụ tiền sản giật. Đối tượng và phương pháp: Nhóm bênh: 20 sản phụ tiền sản giật $\geq 18$ tuổi có thai từ 28 tuân trở lên, thai tự nhiên, không mắc các bệnh cấp và man tính. Nhóm chứng: 20 sản phụ khỏe manh có tuổi me và tuổi thai tương đương, thai tự nhiên, không mắc các bệnh cấp và mạn tính; Cả hai nhóm đều thực hiện xét nghiệm sàng lọc cơ bản trước sinh bình thường, đến khám và điều tri tai Khoa Phu Sản và Viên Tim mach Bệnh viện Bạch Mai trong thời gian từ 08/2019 đến 8/2020.Tंhực hiện siêu âm tim thai và thu thâp thông tin từ hồ sơ bệnh án tại bênh viện theo mẫu bệnh án nghiên cứu thống nhất. Kết quả và kết luân: Chỉ số tim ngực và bề dày các thành tim của thai nhi ở nhóm sản phu TSG lớn hơn so với nhóm chứng $(p<0,001)$. Chức năng tâm thu của thai nhi ở sản phụ TSG giảm hơn so với của thai nhi ở me bình thường, biểu hiện ở sự giảm chức năng tim toàn bộ - tăng chỉ số Tei thất phải $(0,39 \pm 0,02$ ở sản phụ TSG, 0,36 $\pm 0,05$ ở sản phụ thường, $\mathrm{p}=0,022)$ và tăng chỉ số Tei thất trái $(0,42 \pm 0,02$ ở sản phụ TSG và $0,40 \pm 0,04$ ở sản phu thường, $p=0,025)$, trong khi phân suất co rút cơ thất trái không thay đổi $(32,84 \pm 2,09$ ở sản phụ TSG và $35,02 \pm 5,31$ ở sản phụ thường, $p=0,101$ )

Tư khóa: Tiền sản giật, chức năng tim thai

${ }^{1}$ Bênh viên Vinmec Hạ Long

${ }^{2}$ Viện Tim mạch Việt Nam

${ }^{3}$ Trường Đại họ Y Hà Nội

Chịu trách nhiệm chính: Nguyễn Phương Thảo

Email: bacsiphuongthaonguyen@gmail.com

Ngày nhận bài: 23.10.2020

Ngày phản biện khoa học: 25.11.2020

Ngày duyệt bài: 8.12.2020

\section{SUMMARY}

TO EVALUATE THE CHANGES IN FETAL CARDIAC MORPHOLOGY AND FUNCTION IN PRE-ECLAMPSIA PREGNANT WOMEN AT DEPARTMENT OF OBSTETRICS AND GYNECOLOGY AND VIETNAM NATIONAL HEART INSTITUTE OF BACH MAI HOSPITAL

Objective: To evaluate the changes in fetal cardiac morphology and function in pre-eclampsia pregnant women.Subjects and methods: Forty pregnant women, who have some characteristics: greater than or equal to 18 year olds, have 28 weeks of pregnancy or above, spontaneous pregnancy, not suffer from acute and chronic diseases, basic prenatal screening tests are nomal, come for medical examination and treatment at Department of Obstetrics and Gynecology and Vietnam National Heart Institute of Bach Mai Hospital from August 2019 to August 2020.Results and Conclusions: The fetal diastolic function in pregnant women with preeclampsia, as assessed by the $\mathrm{E} / \mathrm{A}$ ratios and the $E$ '/ $A$ ' ratios of the left and right ventricles, were not different from the fetal diastolic function in normal pregnant women $(p>0.05)$. The fetal systolic function in pregnant women with preeclampsia reduced than the fetal systolic function in normal pregnant women, manifested in a decrease in overall cardiac function: Increased RV Tei index (0.39 \pm 0.02 in pregnant women with preeclampsia, $p=0.022$ ) and increased left ventricular Tei index $(0.42 \pm 0.02$ in pregnant women with preeclampsia, $\mathrm{p}=0.025)$.

Keywords: pre-eclampsia, fetal cardiac function

\section{I. ĐĂT VẤN ĐỀ}

Tiên sản giật là bệnh lý tim mạch- sản khoa phức tạp gây ra tử vong và biến chứng nặng nề 